\title{
Authenticity and awareness of English as a lingua franca in English language classrooms
}

\begin{abstract}
Research on the incorporation of the emerging English as a lingua franca (ELF) paradigm into English language teaching has flourished in recent years, foregrounding the necessity of translanguaging practices. However, despite the growing awareness of ELF, teachers still struggle to determine whether and how to adhere to the emerging paradigm. In particular, the authenticity of ELF teaching methods in the English language classroom has not been sufficiently addressed, and therefore, needs to be revamped. The aim of this paper is twofold. On the one hand, it explores the aspect of teachers' ELF awareness in English teaching practices as well as the importance of incorporating authentic ELF materials into the classroom to help learners become ELF-aware and, consequently, competent intercultural speakers. On the other hand, it helps English language teachers, specifically those who have no or marginal exposure to ELF to reflect on the subject they teach, challenging the dominant World Englishes paradigm.
\end{abstract}

KEYwords: Competent intercultural speaker, ELF authenticity, ELF awareness, English teaching practices, translanguaging.

\section{INTRODUCTION}

English as a lingua franca (ELF) has raised an increasing interest in the field of Applied Linguistics over the last two decades. A preliminary introduction to ELF and how it facilitates intercultural communication is interconnected with today's global communication. English demographic trends indicate that the constant movement of people across the world has led to English being used for intercultural communication (Graddol 2006). This supports the view that "today's ideal speaker lives in a heterogeneous society (stratified along increasingly globalised lines) and has to negotiate with different people representing all sorts of power" (Mufwene 2007: 63). An English speaker in a multilingual and multicultural setting has to communicate with a number of other speakers from diverse linguacultural backgrounds and with different levels of language proficiency. The question which arises is whether the English used in such situations should be that of the native speakers or non-native speakers. Moreover, the 
status of English as the lingua franca of our time poses relevant implications for English language teaching (ELT) and learning. Therefore, this paper will attempt to answer the above question, in addition to establishing whether ELF can represent authenticity through authentic language use and how teachers can create opportunities for learners to employ English in lingua franca speech situations.

This article draws on Lopriore's (2017) observations about the importance of the authenticity of ELF inside and outside the multilingual classroom and reframe them due to the necessity of expressly conjoining an ELF-aware approach with the authenticity of ELF. On the one hand, it sets out to encourage English teachers, particularly those who are new to the domain of ELF, to challenge the dominant World Englishes (WEs) paradigm (Jenkins 2000, 2007; Saraceni 2009; Seidlhofer 2004, 2011) through an ELF-aware approach. On the other hand, it advocates that ELF-aware teachers incorporate ELF authentic materials in the classroom to enhance learners' awareness of the diverse uses of English, which is of great importance to a competent intercultural speaker in today's globalised multicultural scenario.

In light of this, the present study addresses the question of the shortage of authentic ELF materials in the English classroom to raise learners' ELF awareness, an issue that has received insufficient attention so far. Specifically, we maintain that, through the use of such authentic materials and ELF itself as an authentic tool of intercultural communication, learners can become aware of the multiple facets of English and develop into competent intercultural speakers, whereas the notions of a competent ELF speaker and competent intercultural speaker often overlap (Taglialatela \& Tardi 2020).

The article is organised as follows: Section 2 illustrates the notion of ELF and its recent evolution to English as a multilingua franca (EMF), and contextualises it in terms of ELT; Section 3 explores the implications of ELF for teachers and learners, with some reflections on teacher training; Section 4 examines how the authenticity of ELF can be achieved by integrating authentic ELF materials into the English classroom; finally, Section 5 draws conclusions and makes some suggestions for future research.

\section{CONTEXTUALISING ELF IN ELT}

A recent study has revealed that more than $80 \%$ of language interactions in the world occur among speakers with different mother tongues whose preferred means of communication is English (Kiczkowiak \& Lowe 2018). This clearly implies that in a broader teaching perspective, in which non-native English speakers (NNESs) can legitimately appropriate the language as well as the native 
English speakers (NESs), the latter can no longer be regarded as the undisputable custodians of the development of English (Poppi 2010). The belief that the English used by NESs is superior to all other varieties of English, which has been termed "native speakerism" by Holliday (2005: 10) and that it should set the linguistic norms in all situations, is erroneous (Fang 2018; Phillipson 1992; Seidlhofer 2020) and needs reconceptualisation, particularly in the ELT context, where, as a general rule, teachers should demonstrate the required pedagogical skills and preparation for the profession prior to being employed based on their native language.

Canagarajah (2007) challenges the construct of ELF with that of Lingua Franca English (LFE), emphasising that languages other than English also exist as lingua franca. Of course, English plays a prominent role as today's global lingua franca. Canagarajah maintains that LFE "belongs to a virtual speech community" in that "LFE speakers are not located in one geographical boundary. They inhabit and practice other languages and cultures in their own immediate localities" (2007: 925), and goes on to say that:

Multilingualism is at the heart of LFE's hybrid community identity and speaker proficiency. A radical implication of this multilingualism is that all users of LFE have native competence of LFE, just as they have native competence in certain other languages and cultures (Canagarajah 2007: 925).

This assertion is in keeping with the updated theory of ELF as EMF, as it foregrounds the inherent multilingualism of global encounters (Jenkins 2015). In particular, EMF is viewed as an intrinsically multilingual means of Englishmedium communication among interactants with a different linguacultural background (Jenkins 2015; Mauranen 2018; Seidlhofer 2018), and is simultaneously considered a conditio sine qua non for professional success and social inclusion. However, for the sake of consistency throughout this paper, we shall use the locution ELF rather than EMF, abiding by Jenkins's (2015: 73) definition, according to which ELF "is available as a preferred contact language in multilingual and multicultural situations".

\subsection{ELF as a resource for ELT}

Graddol (2006: 11) points out that "English is no longer English as we have known it, and have taught it in the past as a foreign language, but is a new phenomenon now recognised as English as a lingua franca". While in Firth's (1996: 240) words, English is the preferred "contact language" among speakers with different linguacultural backgrounds. The current definition of ELF embraces 
its broader function as a multilingual means of communication (Mauranen 2018; Seidlhofer 2018), wherein the two expressions, multilingual and means of communication, define its very nature. Indeed, ELF research has revealed how English and multilingual resources are employed flexibly across geographical boundaries ever since the emergence of ELF (Jenkins 1996, 2000; Seidlhofer 2011). ELF research is no longer conducted with ELF as a framework for reference but is focused on ELF within the framework of multilingualism. In this respect, Jenkins (2015: 77) argues that "English [...] is now conceived as one among many other languages, one resource among many, available but not necessarily used, with ELF defined not merely by its variability but by its complexity and emergent nature". In fact, to enhance communication efficiency and potential, NESs and NNESs alike resort to those multilingual resources in interaction which are present "in their own multilingual verbal repertoire and which they know are part of the listener's repertoire" (Cogo 2016; Margić 2017: 33, after Platt 1977; Seidlhofer 2009). Therefore, ELF proves to be a "multilingual practice" by definition (Jenkins 2015: 63) and makes English a "multilingua franca" (Jenkins 2015: 73). As Margić (2017: 33) puts it, "occasional switching to the interlocutor's [first language] L1, or any other language that the interlocutors share, or modifying English to recall structures in these languages, is an important pragmatic strategy through which both conversational flow and rapport are maintained".

A similar complex milieu requires a rethinking of the tenets of communication in English and, consequently, in English pedagogical practices. In particular, the gradual shift from the stress on "accuracy" and "correctness" to that on "appropriateness" and "intelligibility" (Jenkins 2000, 2007; Seidlhofer 2004, 2011) calls for a reflection on the function of English across the curriculum and the requirement to develop a new kind of language awareness on the teachers' part that reaches far beyond normative grammaticality. Canagarajah (2007: 927) argues that:

we have to judge proficiency, intelligibility, and communicative success in terms of each context and its participants. More importantly, we have to interpret the meaning and significance of the English used from the participants' own perspective, without imposing the researcher's standards or criteria invoked from elsewhere.

This argument is thought-provoking, as English is no longer a foreign language as it used to be within the long-standing WEs paradigm elaborated by Kachru $(1985,1992)$, where the relevance of NESs as language norm providers prevailed. Valdman $(1989,1992)$, for example, advanced the notion of "pedagogical variable norm" as a useful framework for supporting teachers in their decisions about which language variety and sociolinguistic variants to impart to the learners. Although the framework stemmed from a research conducted on French language teaching, it is also applicable to ELT, due to the plurality of WEs. Valdman 
demonstrated that language exists in various forms, which results in different target language norms with the potential to guide foreign or second language learning. Thus, the outcomes of his research still hold empirical implications for ELT, as well as other languages.

Kachru $(1985,1992,2003)$ formulated a concentric three-circle model (i.e., inner, outer, and expanding circles) in a pioneering attempt to define the spread and use of English globally, especially regarding which variety of English should be used in the classroom. According to this model, the inner circle refers to those countries where English is the native language or L1, namely, "the countries where [one can find] the traditional culture and linguistic bases of English" (1992: 356); the outer circle consists of "a large speech community with great diversity and distinct characteristics" (2003: 9); and the expanding circle regards English as an international language, characterised "by performance (or EFL [...]) varieties". The question is to understand in which circle the type of English we teach is included.

Undoubtedly, English performance of the learners across the three circles varies depending on where it is being used. However, through the Kachruvian model, the role of NESs as language norm providers (inner circle) is emphasised, which is in opposition to the fact that the number of NNESs surpasses that of NESs and that English is appropriated by everyone. Indeed, Widdowson (2020) points out that such a norm-providing version "is actually imposed as an ideal norm of usage which most users of English in the world do not conform to, and whose English is regarded as unacceptable [...]". However, this non-conformist exploitation of linguistic resources is nothing but adaptive creativity, which is the real driving force of all communication (Kohn 2019). The fundamentals of how English actually functions in intercultural communication can be noticed because of how ELF is used among speakers from outside the inner circle.

Jenkins $(2000,2007)$ and Seidlhofer $(2004,2011)$, fostering the idea of ELF in intercultural communication, were the first to pay special attention to "intelligibility" rather than "accuracy". Jenkins $(1998,2000)$, in particular, conceived the Lingua Franca Core (LFC), that is, a pronunciation framework enabling ELF speakers to communicate successfully among themselves, with the aim of redefining and reclassifying pronunciation errors to embrace the sociolinguistic facets of regional variation. Theoretically, LFC has come under criticism for aiming to promote and justify any deviation from the norm; however, in practice, it simply identifies when a deviation is functional for communication, thereby contributing to democracy in cross-cultural communication (Jenkins 2000). Thus, LFC responds to the need of intelligibility while facilitating the learning procedure, and still supports the view that ELF speakers can develop their skills to communicate internationally (Taglialatela \& Tardi 2020), such as the ability to adapt to and share their language repertoire with their foreign interlocutor for mutual 
understanding (Cogo 2010). In so doing, Jenkins and Seidlhofer have laid the theoretical foundations of a progressive change in English language pedagogy from teachers' monolingual view of language, where languages are considered separate entities, to a holistic view, where a language is considered as a process, especially in connection with the dynamics of any communicative situation (Piccardo 2020). Reasonably, the variety of English that should be taught is not an NES variety, but a variant ${ }^{1}$ embedding learners' own multilingual repertoire, which they are aware is equally part of their listener's own repertoire.

\subsection{ELF and (trans)languaging}

As contended by García (2011: 7), "language is not something that human beings have, but an ongoing process that exists in languaging", namely, in those language practices of speakers in which multiple discursive resources are necessary. For this reason, teachers need to be guided from the beginning "to develop a pedagogy that utilises fluid, mobile, and multiple discursive resources in [today's] multilingual classrooms" (Zein 2018: 36), thereby shifting from a monolingual to a translanguaging pedagogy, where native languages or L1s are appraised and employed purposely. Through translanguaging, speakers' natural cognitive and linguistic capacities strategically draw on all the available cognitive, semiotic, sensory, and modal resources at their disposal (Paradowski 2020) to interact.

Despite being different in their own right (Kimura \& Canagarajah 2018), the translanguaging and ELF perspectives draw from the common objective of meaning making for mutual understanding (Kimura \& Canagarajah 2018) and are complementary in nature. Translanguaging, in particular, exploits linguistic differences as a resource to express one's unique voice without disregarding linguistic conventions and established varieties (Canagarajah 2013). Consequently, in the educational context, it counters the pressures of prevalent monolingual language $\mathrm{X}$-only policies or two-way bilingual immersion programmes. Ideally, translanguaging not only allows but also encourages teachers to actively draw on learners' semiotic resources (Paradowski 2020), so that they "can incorporate purposeful and systematic discursive modes such as code-switching and translating as part of their everyday way of meaning making" (Zein 2018: 36). Here, a reconceptualisation is required of language education and linguistic competencies, which are focused on the learner rather than the language in its own right.

\footnotetext{
${ }^{1}$ It is worth mentioning that ELF is not a focused variety in its own right, but rather a variant with recurring characteristics when spoken among NNESs (Canagarajah 2007; Laitinen 2020).
} 
However, promoting translanguaging in the ELF context not only implies a paradigm shift but also flatly rejects the dominant language policies such as "English Only" as the "great equalizer" (Woodley \& Brown 2016: 95) which grant NESs great privileges. For both teachers and learners, NESs still represent the linguistic and cultural model to pursue in the English classroom (Moussu \& Llurda 2008) to be better teachers and communicators than their NNES counterparts (Matsuda 2018). Seidlhofer (2004: 212) maintains that "language is so closely and automatically tied up with its native speakers that it is very difficult to open up conceptual space for ELF", as well as that "if English is to function as a lingua franca, and as a means for inclusive communication, it has to be dissociated from the language which is defined in reference to native speaker norms and territories" (Seidlhofer 2020). ELF awareness can make teachers more independent, for they can identify and tailor all sorts of strategies and materials to the learners' requirements more effectively (Svalberg 2016). Nonetheless, as argued by Sifakis (2019: 293), "lesson plans, teacher training curricula, textbooks, policies, and assessment procedures" should be informed "in ways that will render the ELT experience richer and deeper, and closer to a realistic experience of what has come to be global communication via English" [my emphasis]. The need to integrate the authenticity of ELF into the teaching method and materials adopted in the classroom is again acknowledged as relevant in teaching practice, which highlights how ELF research has progressively redirected its attention from the mere linguistic rules and patterns towards its underlying pragmatic uses in specific situations for co-construction of meaning (Hüttner 2009). Teachers therefore need to create a space for the development of learners' ELF awareness in that "linguistic norms are fluid and negotiable ideological constructs" (Zein 2018: 36), broadening at the same time learners' conception of communication beyond the linguistic exchanges with the NESs.

\section{INTEGRATING AN ELF-AWARE APPROACH INTO ELT}

Integrating an ELF-aware approach into the English classroom requires the consideration of both doability issues and related tasks (Kumar Bhowmik 2015). An evaluation of teaching objectives against these factors can help teachers determine more realistic targets for learners. In particular, if the objective is to incorporate ELF awareness into the classroom, teachers will need to develop learners' potential to open up a new space for using English for using English creatively, based on their own linguacultural background and experiences (Kohn 2019). In this sense, an important issue is the acknowledgement of ELF lexicogrammatical features, as the embodiment of a multicultural appropriation of 
English is oriented in such a direction where deviations from the norm are not deficiencies or errors, but peculiar and negotiated features of ELF. Teachers are called to review their teaching methods and materials accordingly, and reflect on their current practices (Dewey 2012) to encourage students to learn reflectively from their own experiences, develop their own requirements of communal communicative success, and further improve their ELF competence (Hoffstaedter \& Kohn 2017; Kohn 2019).

\subsection{Implications and challenges for teachers (and learners)}

There are several challenges that hinder the shift from the traditional ELT approach to a more pragmatic ELF-aware approach in teaching practice. On the one hand, challenges arise from the uncertainty of establishing, applying, and evaluating the appropriate ELF pedagogy - methods, models, and materials especially in a multilingual classroom (Sifakis 2020). On the other hand, teachers' orientations towards non-native English appear fundamentally negative. Nonnative English is still perceived as an inauthentic representation of standard English and, consequently, non-native English teachers (NNETs) often undergo discriminatory practices in the workplace and are marginalised as language teachers (Braine 2010; Trent 2016). Nevertheless, research on the role of NNETs has demonstrated their potential assets such as their knowledge of language and local setting (Llurda 2006; Vodopija-Krstanović \& Vukanović 2011), bringing the rich influences of their local languages and cultural contexts to English. Moreover, they are regarded as "a good learner model", because, as Seidlhofer affirms, "the native speakers know the destination, but not the terrain that has to be crossed to get there: they themselves have not travelled the same route" (1999: 238). Biases against NNETs can be overcome if they are perceived as providing an opportunity for integrating real-life interactions, which involve NNESs - in this case, teachers and learners - in the foreign language classroom and for stimulating teacher reflection and growth (Sifakis 2020). Furthermore, several English language teachers maintain that an ELF-oriented approach is somewhat questionable (Modiano 2009; Seidlhofer 2011; Weber 2013). First, teachers still lack concrete strategies for how to integrate these paradigmatic changes into the language classroom (Dewey 2014) and are hesitant to adopt an ELF approach. Moreover, there still persists the tendency to separate the competencies of researchers ("knowing that") from those of professionals ("knowing how") (Margić \& Vodopsija-Krstanović 2018). Clearly, scholars and professionals conceptualise English in different ways: while ELF scholars think of it in terms of "real-life English language" by focusing on communication, professionals consider it in 
relation to "linguistic standardisation and norms" (Sifakis 2004: 242). Teachers can thus familiarise themselves with ELF research and integrate it into their practice, as long as they can rely on specifically designed materials.

Unfortunately, no easy solution can be provided. For instance, Jenkins (2012: 492) maintains that, regardless of what English language teachers are, or are not recommended to do in a class by researchers, "[...] it is for ELT practitioners to decide whether / to what extent ELF is relevant to their learners in their context". Of course, what English language teachers learn in their training programmes may influence their prospective teaching and beliefs about the language (Bayyurt et al. 2019). Therefore, a critical, comprehensive review of current teacher training programmes and materials is to be conducted to prepare them for the diverse challenges posed by an English language classroom with a multicultural and multilingual environment.

The field of ELT features certain tensions which not only influence teachers' and, consequently, learners' behaviours but also ELT practices in terms of approaches and methods, as these may sometimes cause failures or disruptions of the teaching objectives (Kumar Bhowmik 2015). It is thus important to reflect on how the ELF phenomenon can impact ELT.

Kirkpatrick (2007: 195) argues that teachers wishing to work across the renowned Kachruvian circles (more specifically, in outer and expanding circle countries) "should be able to evaluate ELT materials critically to ensure that [...], either explicitly or implicitly, [these do not] promote a particular variety of English or culture at the expense of others". This argument is both reasonable as well as disputable. Indeed, in multilingual classrooms, and in certain communicative exchanges, the decision regarding the English variety to be adopted depends very much on the type of speakers involved in the interaction (Matsuda 2018: 26). However, it is impossible to predict which English variety will be used on each occasion, and thus, becoming ELF-aware is crucial for teachers to foster learners' self-confidence and success in multilingual / multicultural environments.

\subsection{Becoming ELF-aware}

Calafato (2019:4) contends that "[1]anguage awareness is explicit knowledge about and conscious perception of language, its structure and vocabulary, its teaching and learning, as well as its use in social and cultural contexts", and this clearly involves both cognitive and socio-cultural components. Language awareness allows teachers and learners with the same mother tongue to resort to their L1 knowledge and, consequently, take part in a cross-cultural and cross- 
linguistic reflection of the characteristics detected in their L1, as well as in the target language (Svalberg 2016).

This observation calls into question also the contentious function of culture in ELT. Drawing on the theory that ELF constitutes a neutral and impartial communication code (Louhiala-Salminen, Charles \& Kankaanranta 2005), the issue arises of how language instructors can teach and students can learn the language benchmarked against an NES variety, pretending "to belong to a particular 'national' English speaking culture when they obviously do not" (Pöltzl 2003: 4). Reasonably, new ways of communicating must be considered to recognise the plurality of voices in English on the global stage, with English being used in intercultural communication also at the local level (Leung \& Street 2012; Lopriore 2017). Becoming ELF-aware means to not only understand the principles of how ELF functions (Sifakis 2018), but how ELF functions cannot be taught. Learners can rather be sensitised to this phenomenon through real-life activities which develop their own ELF awareness (Lopriore 2017).

Reviewing the general learner-centred concept of awareness proposed by Newby (2000: 20), which distinguishes between learning, pragmatic, and process awareness, Sifakis (2019) makes a distinction among awareness of language and language use, awareness of learning, and awareness of instructional practices. In particular, he argues that these types of awareness are intertwined and arise simultaneously in teacher education practices but with different perspectives: "language use" is set as the goal of teaching, "instructional practice" refers to the process, and "learning" involves the lesson's content. Nevertheless, in Sifakis's distinction, the centrality of the concept of awareness remains the same as in Newby's proposal.

Although teachers are becoming increasingly aware of the relevance of incorporating an ELF-aware approach into ELT, due to multilingual and multicultural classrooms, they still struggle to adopt and integrate this approach into their classrooms and, consequently, learners often demonstrate their inability to cope with ELF situations. Therefore, teachers need to overcome their resistance to and preconceptions about the integration of an ELF-aware approach into their classroom and adjust both lesson contents and teaching methods to the learning needs of their students. This is the key to help them develop their ELF awareness.

\section{ELF AUTHENTICITY INSIDE AND OUTSIDE THE ENGLISH CLASSROOM}

The notion of authenticity in ELT has been investigated from different perspectives in recent decades, mostly in terms of "the type of constructed vs. authentic language samples as used in textbooks and teaching materials" (Lopriore 
2017: 188). However, the way teachers may use authentic materials can even make them inauthentic (this will be discussed in Subsection 4.1). Breen (1985: 61) stresses that language teachers are "continually concerned with four types of authenticity: (1) authenticity of the texts which they may use as input data for learners; (2) authenticity of the learners' own interpretations of such texts; (3) authenticity of tasks leading to language learning; and (4) authenticity of the social situation of the language classroom". Despite this classification, Breen's distinction highlights that the concept of authenticity has no singular meaning (cf. Widdowson 1990).

The question of authenticity has recently gained new ground due to globalisation, the use of information and communication technology (ICT), the emergence of new forms of authenticity, such as social media, and the rising relevance of localised language use. The last factor in particular as well as the importance of social context are underlined by current research on ELF which also challenges the essential nature of authenticity (Pinner 2016; Preisler 2014). For example, some researchers ponder whether ELF can represent authenticity through authentic language use, but ELF has proved to aptly represent such authenticity, being widely exploited in multilingual and multicultural situations, also in virtual ones, and going beyond the material used in the classroom.

In fact, teaching modalities, such as distance learning, online courses, webinars, virtual international conferences and meetings, have been reshaped owing to the COVID-19 pandemic, and the extent to which individuals have been exposed to authentic language, connecting through the web and social media, and through different varieties of English merging into ELF. ELF can operate concretely in real-life contexts and can be regarded as the learning tool as well as the objective. Pinner (2015: n.a.) suggests that "[a] way of thinking about authenticity is from a wider perspective, something that encompasses not only the materials being used and the tasks set to engage with them, but also the people in the classroom and the social context of the target language", establishing a continuum among the social, linguistic, and contextual components. The type of English spoken in multilingual classrooms is fundamentally an authentic lingua franca for intercultural communication (Canagarajah 2007).

In this sense, teacher development programmes need to be distanced from "the traditional monolingual approach to instruction" (Calafato 2019: 2) and should enable English language teachers to integrate ELF approaches into the language classroom, particularly in multilingual and multicultural ones. While on the one hand, an ELF-informed teaching approach is required for learners who must be acquainted with the multiple facets of English, on the other hand, ELF is necessary as an authentic communicative tool in multilingual and multicultural environments, this being the common ground for communication (Jenkins 2015). 
Research findings ${ }^{2}$ reveal that teachers are increasingly becoming conscious of the new communicative needs in multilingual classes since English arises in different instantiations - ELF, among others. On this basis, teachers' non-native status is central to managing classroom dynamics: for example, the need for learners to act as competent intercultural communicators (Byram 1997), thus accepting other learners' forms of translanguaging in communication, or the teacher's need to use authentic input and tasks. In this respect, out-of-school experiences and the use of ICT and social media are of great help for learners due to their authenticity. As Musthafa, Hamied and Zein (2019: 180) emphasise, "[it is] important to empower students to become independent, strategic learners, to encourage every individual learner to take ownership of their own learning [...] to create opportunities for students to use English for communicative purposes in lingua franca situations", but the question is how to achieve this goal. The following subsection attempts to provide a response.

\subsection{ELF authenticity in teaching material}

The debate on authenticity has always regarded content found in newspapers, magazines, radio, and TV broadcasts, together with internet content as authentic material. These are spontaneous, natural, and diverse texts, which were originally produced for non-pedagogical purposes (Gilmore 2007). No materials, however, are authentic in their own right. It is those who use them, that is, teachers and learners, who make them authentic (cf. Widdowson 1978). According to Pinner (2015: n.a.), "authenticity refers to how learners engage with the material used in the classroom and how they relate to it". A teacher could employ authentic material but use it inauthentically. For example, would using an English language newspaper in the classroom and asking learners to read an article, identify certain grammatical features, and then inviting them to copy something into their notebooks really be authentic? Even though for many people newspapers are a typical example of authentic texts, what will happen in a similar situation is not really authentic language learning, but rather an unproductive focus on grammar, as newspapers themselves are not an expression of "spontaneous" language. Newspapers can be used authentically if, for example, they can stimulate spontaneous in-class discussions.

\footnotetext{
${ }^{2}$ See, for instance, the transnational ENRICH Project (2018-2021) which, drawing on current thinking about multilingualism and ELF, defies the traditional approach to English as a monolithic entity devoid of any relevance to other languages and cultures, promoting an innovative, researchbased view of the English classroom as an inherently multilingual environment.
} 
Some teachers, however, are reluctant to the introduction of novelties deriving from the authentic and intercultural use of English, as this is considered counterintuitive and even counterproductive (Margić \& Vodopija-Krstanović 2018). For example, students are thought to lose out on the possibility of learning a standard variety of English, which may be useful in their future lives for working or studying in native English-speaking countries. In a similar manner, there is concern that an ELF approach to education suggests that native standards are unattainable (Groom 2012). It is worth clarifying that the point is not to disregard the native English varieties, but to enlighten learners on the different varieties of English, which can contribute to making them successful intercultural communicators (Lopriore 2017).

The apparent objective of authenticity seems currently to suggest that we have authenticity in the real world and pedagogy in the classroom. Very often, textbooks and materials that teachers employ do not reflect an authentic expression of the world, as ELT textbooks still represent native-speaker norms and cultures (Calafato 2019; Lopriore 2017). It is now necessary that they look at "real contexts, spontaneous language, and genuine needs" (Newby 2000: 16). A more focused integration of inputs and tasks displaying examples of interactions which involve native and non-native users of English in various settings is required, as a reflection of what happens outside the classroom. It is crucial to redesign, for example, listening and speaking inputs, because ELF is mostly focused on what happens in spoken interactions. Tasks should engage learners in authentic ELF use and foster their deeper appreciation of the function of English as an effective means of interaction involving native and non-native speakers.

This has benefits for learners. Giving learners a "voice" in learning activities is what makes such activities more authentic (Leung \& Lewkowicz 2017: 87), as their voice often comes from outside classroom relationships, or even from within the classroom if multilingual. Learners need to be exposed to the language used in real life to draw their attention to features of authentic speech, that is, "natural rhythm and intonation, natural starts and stops, incomplete sentences, hesitations, fillers, etc." (Tomlinson 2010: 83), which is something that rarely happens in language classrooms and textbooks. As argued by Lopriore (2017), a way to encourage learners to 'practise' authenticity is to use authentic materials in the tasks they are assigned, where, by resorting to their own language communicative strategies, they can authenticate their language use. In fact, to embed an ELF approach in language teaching and, consequently, foster learners' ELF awareness, traditional materials such as course books or grammar books should be implemented with a variety of out-of-classroom authentic resources and highlight the diverse instantiations of English. Nonetheless, a valuable contribution towards the development of learners' ELF awareness could be 
made by teachers' teamwork to build strong local communities. It is the local teachers who know the classroom and their (multilingual and multicultural) students (González 2010), and reasonably, they are the ones who know how to authenticate, or help learners to authenticate the use of language.

\section{CONCLUSIONS AND RESEARCH PROSPECTS}

This article has pictured how ELF performs in English language pedagogy. From the teacher's perspective, English language teachers are becoming aware of the impact of ELF on ELT, particularly in multilingual and multicultural environments. However, it is still unclear in what specific context and to what extent they can integrate ELF-related issues into their teaching practice, specifically because of the shortcomings of ad hoc material. To remedy this situation, teachers are called on to challenge the traditional ELT paradigm and, through attentive evaluation of the teaching context, incorporate an ELF-aware approach into the classroom.

From the learner's perspective, it is crucial that English pedagogy consider the authentic use of the materials employed in the classroom, as this can help engage learners in a wide range of real-life communicative contexts, making them aware of the diverse facets of English and what being a competent intercultural speaker implies, while preserving their linguacultural identity.

ELF is a major transdisciplinary field, and our focus on pedagogy has provided a background for in-depth discussion of other spheres, such as language policy making, language material development and implementation, evaluation, and teacher education. As discussed, teachers still lack adequate training on how to incorporate an ELF-aware perspective into their teaching, which is permeated by the traditional WEs paradigm and considers native speakers' English as the ultimate ideal to aspire to in both teaching and learning practices. Nevertheless, the elusive NES model as the benchmark in ELT is no longer suitable for our multifaceted reality. Sifakis and Bayyurt (2018: 464) contend that "being an ELF-aware teacher means finding ways to empower one's learners as competent non-native users of English, essentially prompting them to become ELF aware users themselves". To this end, it is vital for teachers to have an outlook that transcends the classroom context and the mere use of course books, and become authors themselves in their own locality. It is important in the first place to engage them in supervised lesson planning undertaken from a more critical and less textbook-focused standpoint (Dewey 2014), promote their critical reflection on traditional practices, and include authentic tasks in their teaching. Further research should thus be conducted in these contexts, as the goal is to align teaching and learning practices with our reality outside the classroom. Research should 
also be carried out in respect to teachers' own conceptualisation of the English language, as their personal beliefs may influence and impact the way they teach. ICT had already been playing a vital role in recent years; however, because of the COVID-19 pandemic, its contribution in fostering ELF-aware practices has become even more important, and research should be conducted also in this field to examine which tools could trigger learners' lively interest in using ELF communication strategies actively.

This study adds to the debate on ELF awareness in ELT, espousing the integration of ELF authentic material into the classroom to raise ELF awareness, as this is an aspect which is still needing special attention in current teaching and learning practices. In so doing, it supports, to a certain extent, English language teachers, particularly those who have little or no exposure to ELF, in reflecting on the subject they teach.

\section{REFERENCES}

Bayyurt, Y. / Kurt, Y. / Öztekin, E. / Guerra, L. / Cavalheiro, L. / Pereira, R. (2019). English language teachers' awareness of English as a lingua franca in multilingual and multicultural contexts. Eurasian Journal of Applied Linguistics, 5 (2), 185-202. DOI: 10.32601/ ejal.599230.

Braine, G. (2010). Non-native speaker English teachers: Research, pedagogy, and professional growth. New York: Routledge.

Breen, M. (1985). Authenticity in the language classroom. Applied Linguistics, 6 (1), 60-70.

Byram, M. (1997). Teaching and assessing intercultural communicative competence. Clevedon: Multilingual Matters.

Calafato, R. (2019). The non-native speaker teacher as proficient multilingual: A critical review of research from 2009-2018. Lingua, 227, 102700. DOI: 10.1016/j.lingua.2019.06.001.

Canagarajah, S.A. (2007). Lingua franca English, multilingual communities, and language acquisition. The Modern Language Journal, 91, 923-939. http://www.personal.psu.edu/asc16/ MLJ91.5LinguaFranca.pdf [access: 12.03.2020].

Canagarajah, S.A. (2013). Literacy as a translingual practice: Between communities and classrooms. London: Routledge.

Cogo, A. (2010). Strategic use and perceptions of English as a lingua franca. Poznań Studies on Contemporary Linguistics, 46 (3), 295-312. DOI: 10.2478/v10010-010-0013-7.

Cogo, A. (2016). 'They all take the risk and make the effort': Intercultural accommodation and multilingualism in a BELF community of practice. In: L. Lopriore / E. Grazzi (eds.), Intercultural communication: New perspectives from ELF (pp. 365-383). Rome: Roma TrE-Press.

Dewey, M. (2012). Towards a post-normative approach: Learning the pedagogy of ELF. Journal of English as a Lingua Franca, 1 (1), 141-170.

Dewey, M. (2014). Pedagogic criticality and English as a lingua franca. ATLANTIS - Journal of the Spanish Association of Anglo-American Studies, 36 (2), 11-30.

ENRICH Project (2018-2021). http:/ /enrichproject.eu/ [access: 25.01.2021].

Fang, F. (2018). Native-speakerism revisited: Global Englishes, ELT and intercultural communication. Indonesian Journal of English Language Teaching, 13 (2), 115-129. 
Firth, A. (1996). The discursive accomplishment of normality. On 'lingua franca' English and conversation analysis. Journal of Pragmatics, 26, 237-259. DOI: 10.1016/0378-2166(96)00014-8.

García, O. (2011). Translanguaging of Latino kindergarteners. In: K. Potowski / J. Rothman (eds.), Bilingual youth: Spanish in English speaking societies (pp. 33-55). Amsterdam: John Benjamins.

Gilmore, A. (2007). Authentic materials and authenticity in foreign language learning. Language Teaching, 40, 97-118. DOI: 10.1017/S0261444807004144.

González, A. (2010). English and English teaching in Colombia: Tensions and possibilities in the Expanding circle. In: A. Kirkpatrick (ed.), The Routledge handbook of World Englishes (332-351). London / New York: Routledge.

Graddol, D. (1997). The future of English. London: The British Council.

Graddol, D. (2006). English next. Milton Keynes: The British Council.

Groom, C. (2012). Non-native attitudes towards teaching English as a lingua franca in Europe. English Today, 28 (1), 50-57. DOI: 10.1017/S026607841100068X.

Hoffstaedter, P. / Kohn, K. (2017). Learner agency and non-native speaker identity in pedagogical lingua franca conversations: Insights from intercultural telecollaboration in foreign language education. Computer Assisted Language Learning, 30 (5), 351-367. DOI: 10.1080/09588221.2017.1304966.

Holliday, A. (2005). The struggle to teach English as an international language. Oxford: Oxford University Press.

Hüttner, J. (2009). Fluent speakers - fluent interactions: On the creation of (co)-fluency in English as a lingua franca. In: A. Mauranen / E. Ranta (eds.), English as a lingua franca: Studies and findings (pp. 274-297). Newcastle, UK: Cambridge Scholars Publishing.

Jenkins, J. (1996). Native speaker, non-native speaker and English as a foreign language: Time for a change. IATEFL Newsletter, 131, 10-11.

Jenkins, J. (1998). Which pronunciation norms and models for English as an international language? ELT Journal, 52, 119-126.

Jenkins, J. (2000). The phonology of English as an international language. Oxford: Oxford University Press. Jenkins, J. (2007). Attitude and identity. Oxford: Oxford University Press.

Jenkins, J. (2012). English lingua franca from the classroom to the classroom. ELT Journal, 66 (4), 486-494. DOI: $10.1093 /$ elt/ccs040.

Jenkins, J. (2015). Repositioning English and multilingualism in English as a lingua franca. Englishes in Practice, 2, 49-85. DOI: 10.1515/eip-2015-0003.

Kachru, B.B. (1985). Standards, codification and sociolinguistic realism: The English language in the Outer circle. In: R. Quirk / H. Widdowson (eds.), English in the world (pp. 11-30). Cambridge: Cambridge University Press.

Kachru, B.B. (1992). Teaching World Englishes. In: B.B. Kachru (ed.), The other tongue. English across cultures (2nd ed.) (pp. 355-365). Urbana, IL: University of Illinois Press.

Kachru, B.B. (2003). Liberation linguistics and the Quirk concern. In: B. Seidlhofer (ed.), Controversies in Applied Linguistics (pp. 19-33). Oxford: Oxford University Press.

Kiczkowiak, M. / Lowe, R.J. (2018). Teaching English as a lingua franca: The journey from EFL to ELF. Peaslake, Surrey: Delta Publishing.

Kimura, D. / Canagarajah, S. (2018). Translingual practice and ELF. In: J. Jenkins / J.C. Baker / M. Dewey (eds.), The Routledge handbook of English as a lingua franca (pp. 295-308). London: Routledge.

Kirkpatrick, A. (2007). World Englishes: Implications for international communication and English language teaching. Cambridge: Cambridge University Press.

Kohn, K. (2018). MY English: A social constructivist perspective on ELF. Journal of English as a Lingua Franca, 7 (1), 1-24. DOI: 10.1515/jelf-2018-0001.

Kohn, K. (2019). Lingua franca pedagogy. Emancipating the foreign language learner. Paper presented at ASIA TEFL 2019, Bangkok, 27-29 June 2019. 
Kumar Bhowmik, S. (2015). World Englishes and English language teaching: A pragmatic and humanistic approach. Colombian Applied Linguistics Journal, 17 (1), 142-157. DOI: 10.14483/ udistrital.jour.calj.2015.1.a10.

Laitinen, M. (2020). Empirical perspectives on English as a lingua franca (ELF) grammar. World Englishes, 39 (3), 427-442. DOI: 10.1111/weng.12482.

Leung, C. / Lewkowicz, J. (2017). Second language literacies: Evolving understandings. In: B. Street / S. May (eds.), Encyclopedia of language and education (pp. 169-180). New York: Springer.

Leung, C. / Street, B. (2012). Linking EIL and literacy: Theory and practice. In: L. Alsagoff / S.L. McKay / G. Hu / W.A. Renandya (eds.), Principles and practices for teaching English as an international language (pp. 85-103). London / New York: Routledge.

Llurda, E. (2006). Looking at the perceptions, challenges, contributions... Or the importance of being a non-native teacher. In: E. Llurda (ed.), Non-native language teachers: Perceptions, challenges and contributions the profession (pp. 1-9). New York: Springer.

Lopriore, L. (2017). Revisiting language teaching materials in a time of change. Revista A Cor das Letras, 18, 182-199. DOI: 10.13102/cl.v18iEspecial.2668.

Louhiala-Salminen, L. / Charles, M. / Kankaanranta, A. (2005). English as a lingua franca in Nordic corporate mergers: Two case companies. English for Specific Purposes, 24, 401-421.

Margić, B.D. (2017). Communication courtesy or condescension? Linguistic accommodation of native to non-native speakers of English, Journal of English as a Lingua Franca, 6 (1), 29-55. DOI: 10.1515/jelf-2017-0006.

Margić, B.D. / Vodopija-Krstanović, I. (2018). English language education in Croatia: Elitist purism or paradigmatic shift? In: Z. Tatsioka / B. Seidlhofer / N. Sifakis / G. Ferguson (eds.), Using English as a lingua franca in education in Europe: English in Europe (pp. 51-72). Berlin: De Gruyter / Mouton.

Matsuda, A. (2018). Is teaching English as an international language all about being politically correct? RELC Journal, 49 (1), 24-35. DOI: 10.1177/0033688217753489.

Mauranen, A. (2018). Conceptualizing ELF. In: J. Jenkins / W. Baker / M. Dewey (eds.), The Routledge handbook of English as a lingua franca (pp. 7-24). London / New York: Routledge.

Modiano, M. (2009). EIL, native-speakerism and the failure of European ELT. In: F. Sharifian (ed.), English as an international language: Perspectives and pedagogical issues (pp. 58-77). Clevedon UK: Multilingual Matters.

Moussu, L. / Llurda, E. (2008). Non-native English-speaking English language teachers: History and research. Language Teaching, 41 (3), 315-348. DOI: 10.1017/S0261444808005028.

Mufwene, S.S. (2007). Population movements and contacts: Competition, selection and language evolution. Journal of Language Contact, 1, 63-91. http:/ / mufwene.uchicago.edu/ publications/ POPULATION_MOVEMENTS_AND_CONTACTS.pdf [access: 24.02.2020].

Musthafa, B. / Hamied, F.A. / Zein, S. (2019). Enhancing the quality of Indonesian teachers in the ELF era. Policy recommendations. In: S. Zein (ed.), Teacher education for English as a lingua franca. Perspectives from Indonesia (pp. 174-190). Abingdon UK: Routledge.

Newby, D. (2000). Authenticity. In: A.B. Fenner / D. Newby (eds.), Approaches to materials design in European textbooks: Implementing principles of authenticity, learner autonomy, cultural awareness (pp. 16-23). Graz: Council of Europe. http://archive.ecml.at/documents/materials.pdf [access: 10.01.2020].

Paradowski, M.B. (2020). Pedagogical translanguaging in multicultural classrooms: Potential and bounds. Paper presented at the 2nd international conference on Communication in Multicultural Society (CMSC 2020), Moscow, Russia, 10-12 December 2020.

Phillipson, R. (1992). Linguistic imperialism. Oxford: Oxford University Press. 
Piccardo, E. (2020). The CEFR descriptors for mediation \& the dynamic nature of language learning. Paper presented during the videoconference The CEFR Companion volume: A key resource for inclusive plurilingual education. Council of Europe, 16th December 2020.

Pinner, R.S. (2015). What we talk about when we talk about authenticity. Uniliterate - Language Learning and Academic Literacies. https://uniliterate.com/2015/05/talk-talk-authenticity/\#. Xs_i3GgzbIU [access: 23.01.2021].

Pinner, R.S. (2016). Reconceptualising authenticity for English as a global language. Bristol: Multilingual Matters.

Platt, J.T. (1977). A model for polyglossia and multilingualism (with special reference to Singapore and Malaysia). Language in Society, 6 (3), 361-378.

Pöltzl, U. (2003). Signalling cultural identity: The use of L1 / Ln in ELF. Vienna English Working Papers, 12, 3-23.

Poppi, F. (2010). Investigating ELF group membership: A case study focusing on The Baltic Times. In: R. Facchinetti / D. Crystal / B. Seidlhofer (eds.), From international to local English - And back again (pp. 93-113). Bern: Peter Lang.

Preisler, B. (2014). Lecturing in one's first language or in English as a lingua franca: The communication of authenticity. Acta Linguistica Hafniensia, 46 (2), 218-242. DOI: 10.1080/03740463.2014.966603.

Saraceni, M. (2009). Relocating English: Towards a new paradigm for English in the world. Language and Intercultural Communication, 9, 175-186. DOI: 10.1080/14708470902748830.

Seidlhofer, B. (1999). Double standards: Teacher education in the Expanding circle. World Englishes, 18 (2), 233-245. DOI: 10.1111/1467-971X.00136.

Seidlhofer, B. (2001). Closing a conceptual gap: The case for a description of English as a lingua franca. International Journal of Applied Linguistics, 11 (2), 133-158. DOI: 10.1111/1473-4192.00011.

Seidlhofer, B. (2004). Research perspectives on teaching English as a lingua franca. Annual Review of Applied Linguistics, 24, 209-239. DOI: 10.1017/S0267190504000145.

Seidlhofer, B. (2009). Common ground and different realities: World Englishes and English as a lingua franca. World Englishes, 28 (2), 236-245. DOI: 10.1111/j.1467-971X.2009.01592.x.

Seidlhofer, B. (2011). Understanding English as a lingua franca. Oxford: Oxford University Press.

Seidlhofer, B. (2018). Standard English and the dynamics of ELF variation. In: J. Jenkins / W. Baker / M. Dewey (eds.), The Routledge handbook of English as a lingua franca (pp. 85-100). London / New York: Routledge.

Seidlhofer, B. (2020). Yours inclusively: ELF communication. Paper presented at TIES Conference 2020, Naples, 27-29 February 2020.

Sifakis, N. (2004). Teaching EIL - Teaching international or intercultural English: What teachers should know? System, 32 (2), 237-250. DOI: 10.1016/j.system.2003.09.010.

Sifakis, N. (2019). ELF awareness in English language teaching: Principles and processes. Applied Linguistics, 40 (2), 288-306. DOI: 10.1093/applin/amx034.

Sifakis, N. (2020). Two obstacles to enabling change in ELF-aware teacher education and how to overcome them. Revista Estudos Linguísticos e Literários, 65, 104-117. DOI: 10.9771/ell.v1i65.36471.

Svalberg, A. (2016). Language awareness. In: G. Hall (ed.), The Routledge handbook of English language teaching (pp. 399-412). London: Routledge.

Taglialatela A. / Tardi G. (2020). ELF pedagogy and awareness: An action research applied to Italian tertiary students in ELF Skype interactions. Quaderni di Linguistica e Studi Orientali (QULSO) [Working Papers in Linguistics and Oriental Studies], 6, 313-334. DOI: 10.13128/ qulso-2421-7220-9705.

Tomlinson, B. (2010). Principles for effective materials development. In: N. Harwood (ed.), English language teaching materials: Theory and practice (pp. 81-108). Cambridge: Cambridge University Press. 
Trent, J. (2016). The NEST-NNEST divide and teacher identity construction in Hong Kong Schools. Journal of Language, Identity \& Education, 15 (5), 306-320. DOI: 10.1080/15348458.2016.1214587.

Valdman, A. (1989). Classroom foreign language learning and language variation: The notion of pedagogical norms. In: M.R. Eisenstein (ed.), The dynamic interlanguage: Empirical studies in second language acquisition (pp. 261-277). New York: Plenum Press.

Valdman, A. (1992). Authenticity, variation, and communication in the foreign language classroom. In: C. Kramsch / S. McConnell-Ginet (eds.), Text and context. Cross-disciplinary perspectives on language study (pp. 79-97). Lexington, MA: D.C. Heath.

Vettorel, P. (2019). Communication strategies and co-construction of meaning in ELF: Drawing on "multilingual resource pools". Journal of English as a Lingua Franca, 8 (2), 179-210. DOI: 10.1515/jelf-2019-2019.

Vodopija-Krstanović, I. / Vukanović, M.B. (2011). EFL students' perspectives on English: The (widening) gap between ideals and practices. Brazilian Journal of Applied Linguistics - Special Issue on Language Policy, 12 (2), 285-309. DOI: 10.1590/S1984-63982012000200004.

Weber, E. (2013). English as a lingua franca and appropriate teacher competence. In: Y. Bayyurt / S. Akcan (eds.), ELF 5 - Proceedings of the Fifth International Conference of English as a Lingua Franca (pp. 7-13). Boğaziçi: Boğaziçi University Press.

Widdowson, H. (1978). Learning language as communication. Oxford: Oxford University Press.

Widdowson, H. (1990). Aspects of language teaching. Oxford: Oxford University Press.

Widdowson, H. (2020). English beyond the pale: The language of outsiders. Paper presented at TIES Conference 2020, Naples, Italy, 27-29 February 2020.

Woodley, H. / Brown, A. (2016). Balancing windows and mirrors: Translanguaging in a multilingual classroom. In: O. Garcia / T. Kleyn (eds.), Making meaning of translanguaging: Learning from classroom moments (pp. 83-99). New York: Routledge.

Zein, S. (2018). From EFL to ELF: Implications for teacher education. In: S. Zein (ed.). Teacher education for English as a lingua franca: Perspectives from Indonesia (pp. 21-40). New York: Routledge.

Received: 27.06.2020; revised: 31.03.2021

\section{ANTONIO TAGLIALATELA}

Università degli Studi della Tuscia

taglialatela@unitus.it

ORCID: 0000-0002-7328-2681 
